\title{
A Note on Quotations
}

In quotations, $\mathrm{u}, \mathrm{v}, \mathrm{i}, \mathrm{j}$, and $\mathrm{w}$ have been normalized, and contractions have been expanded; otherwise, quotations are given as they appear in the editions cited. In the case of early books that do not include page numbers, citations are to signature numbers. Signatures are the marks placed by the printer at the beginning of each gathering, or section, to show how the book is organized. The marks are usually letters or combinations of letters, but they may also be symbols, such as asterisks or pilcrows. Thus sig. $\mathrm{A} 2^{\mathrm{r}}$ means the first side (recto) of the second leaf of the gathering marked A. The second side, or verso, would be $\mathrm{A}^{v}$. Shakespeare quotations are from the New Pelican editions, edited by Stephen Orgel and A. R. Braunmuller. 
